\title{
Increasing company innovation in Russia: developing employee engagement through leadership and knowledge culture
}

\author{
Ekaterina Baidina*, Natalya Molodchik, Natalya Nagibina
}

Perm National Research Polytechnic University, Komsomolski pr., 29, Perm, Russian Federation

Abstract

The article examines the impact of knowledge culture and transformational leadership on employee engagement and company innovation. The partial least square is applied to the data based on the questionnaire survey of the top and middle managers of 110 different Russian enterprises. The study reveals a significant positive impact of employee engagement on company innovation, as well as an empirical evidence of significant positive influence of knowledge culture and transformational leadership on employee engagement.

\section{Introduction}

In the post-pandemic period, for their strategic stability, an increasing number of companies are studying the factors of the formation and development of innovative activities of personnel. Innovations in the form of breakthrough ideas allow obtaining new products, improving services, increasing the efficiency of business processes and thereby ensuring the company's competitiveness [1]. The combination of organizational ideas, people involved and effective technology in any business delivers meaningful and sustainable results. An increase in engagement by $5 \%$ in a year gives a growth in the company's revenue by $3 \%$ [2].

In modern management, engagement is called a business asset, which is comprehensively studied and enhanced. In this study, the authors suggest that transformational leadership and a culture of knowledge increase employee engagement in production activities, which in turn has a positive impact on the growth of innovations. The influence of these factors will be tested empirically.

The purpose of the presented article is "to identify the influence of the culture of knowledge and transformational leadership on the formation of personnel engagement in order to increase the number of innovations in the organization."

\section{Methodology of the study}

The authors use structural equation modelling in particular partial least square technique in order to estimate the impact of leadership and knowledge culture employee engagement and its further influence on company's innovation. Partial least square allows modeling unobservable latent variables of the study, which are constructs o interest that cannot be measured directly. In order to measure such constructs, the researcher should build a theoretical model and describe it with the help of several observable variables [3]. It means that latent variables are measured indirectly and measurement errors should be taken into account by describing results. For this study the authors construct 4 latent variables, namely, innovation, engagement, transformational leadership and knowledge culture. They were identified through the questionnaire addressed to top management of companies. The latent variable is represented by the system of equations (1):

$$
\left\{\begin{array}{l}
\mathrm{x}_{1}=\alpha_{1}+\beta_{1} \mathrm{X}+\varepsilon \cdot \mathrm{x}_{1} \\
\mathrm{x}_{2}=\alpha_{2}+\beta_{2} \mathrm{X}+\varepsilon \cdot \mathrm{x}_{2} \\
\mathrm{x}_{3}=\alpha_{3}+\beta_{3} \mathrm{X}+\varepsilon \cdot \mathrm{x}_{3} \\
\mathrm{x}_{4}=\alpha_{4}+\beta_{4} \mathrm{X}+\varepsilon \cdot \mathrm{x}_{4}
\end{array}\right.
$$

where $\alpha_{i}$ is a constant; $\beta_{i}$ is the regression coefficient; and $\varepsilon . \mathrm{x}_{i}$ is the error term.

The smartPLS software is applied to estimate the system of several equations simultaneously. As a result, the researcher obtains regression coefficients, variation and covariance of independent variables. The validity and reliability of the model is evaluated with the help of Cronbach's alpha (CA) and Average Value Extracted (AVE). In particular, the coefficient of Cronbach's alpha should be greater than 0.8 . In this case one can state a high internal consistency of latent variable meaning that questions (metrics) describe one phenomenon. For Average Variance Extracted the estimates should exceed 0.6 in order to state a high discriminant validity of latent constructs.

The authors use previous theoretical and empirical studies for developing metrics which are included in the questionnaire survey. The top and middle managers of Russian enterprises participated in the study. The final database consists of 110 observations which is equal the number of enterprises. Descriptive statistics show that more than $75 \%$ of respondents had been working at the enterprise for more than 3 years. Considering industry 
characteristics, most of the enterprises are from manufacturing, namely $64 \%$, the service sector is presented by $22 \%$, the IT industry $-9 \%$ and trade representatives are $5 \%$.

According to the criteria of the number of employees, $32 \%$ of enterprises can be classified as small and medium-sized, $65 \%$ are large and $3 \%$ are superlarge enterprises. It should be noted that almost all enterprises that participated in the survey are actively engaged in innovative activities in all types of innovations. At the same time, product and technological innovations stand out, the volume of which increased for most of the surveyed enterprises.

During the survey, the presence of knowledge culture, transformational leadership, employee engagement, company innovation was assessed on a 5point Likert scale. This scale identifies " 1 " as the absence of this practice at the enterprise, "2" means rare use of this practice, " 3 " - the practice is used from time to time, "4" corresponds with regular usage of the practice, and " 5 " - the practice is used on an ongoing basis. The data collection was organized in the period from August 2019 to February 2020. The survey was shared with the help of the Google Forms toolkit. This instrument allows sending a link to the online form to the respondent and then make data analysis.

\section{Theoretical and empirical justification of latent constructs}

\subsection{Innovation}

The experience of successful companies proves that it is innovative performance that ensures sustainable development in the future.

A lot of studies [4] are devoted to the definition, composition, structure, measurements, mechanisms and risks of innovation and innovation potential management. From the standpoint of strategic and HR management, the study of the sources and drivers of innovation development made it possible to determine the vector of the formation of the innovation environment. The involved employee, being an innovator [5] / inventor / entrepreneur [6], initiates innovation activities in the organization, thus increasing the number of innovations.

The model was based on technological, product and managerial innovations [1]; marketing innovations were not taken into account, since in the calculations the factor load for this element turned out to be below the norm. The selected elements (types of innovations) have high discriminant validity $(\mathrm{AVE}=0.720)$ and are internally consistent $(\mathrm{CR}=0.806)$.

In any business, meaningful and sustainable results will be provided by a combination of organizational ideas, people involved and effective technologies [2].

\subsection{Employee engagement}

The logic of the formation of metrics for assessing engagement is based on the concept, forms of manifestation, conditions and factors affecting engagement.

Employee engagement theory has revolutionized management practice. More than 30 years have passed since 1990 when W. Kahn [7] published his seminal article on personal involvement in work.

In his research, he concludes that based on their own experience in the work environment, employees make decisions about the degree of their involvement.

Since then, interest in engagement research has grown every year. To improve the competitiveness of a company in a rapidly changing world [8], researchers are constantly studying the phenomenon of involvement. To date, a staggering array of theories, concepts, definitions and measurements have been developed [9]. Kahn W. [7] considers involvement from the perspective of personal role participation: cognitive, emotional, psychological expression of the personality, the true self. Shuck B. [10] examines engagement from the perspective of attitudes towards work tasks and assignments. In contrast to burnout, engagement refers to an activated, positive state of mind directed toward work assignments.

Bailey C., Madden A., Alfes K., Fletcher L. [11] pooled the results of 214 studies, presenting the meanings, antecedents, and outcomes of engagement for the organization and well-being of the employee. The authors identified six different conceptual approaches to engagement, as well as a theoretical rationale for engagement within the "job requirements - resources" framework with the dominant concept of "work engagement" by the Utrecht Group. Five groups of factors preceding involvement have been identified: 1 . psychological states; 2. working design; 3. leadership; 4. organizational and team factors; 5. organizational interventions.

Therefore, the formation of observable variables for assessing engagement was based on the following models:

- Gallup. The famous $\mathrm{Q}^{12}$ Gallup Access questionnaire contains 12 questions [8]-elements describing the fundamental psychological requirements for unlocking human potential.

- Culture Amp [12]. Since 2011 and by the time of the study in $2018(1200+$ companies from more than 120 industries), in the "Standard" format, the following main ones were identified: training and development, leadership, focus on service and quality.

- Kincentric. According to Kincentric data, worldwide engagement is stable $(65 \%)$ and has increased by $1 \%$ in recent years (data from 2019 [2]). The questionnaire is based on a concept containing a bunch of 3 indicators: speaks, stays and aspires, and includes 6 questions, 2 for each indicator. Speaks 
(speaks positively about the organization, conversing with colleagues, potential employees and clients), stays (feels a sense of belonging and wants to be a part of the company), aspires (is motivated to make additional efforts to achieve success in his work and for the company as a whole).

In the model, the latent construction "Engagement" is defined by three variables. They are shown in Table 1. These elements have high discriminant validity $(\mathrm{AVE}=0.639)$, are internally consistent $(\mathrm{CR}=0.716)$ and reflect the high explanatory power of each of the elements of the latent construct.

The authors' research interest is based on Kahn's finding that engagement is not static; it fluctuates with the employee's experience, which is influenced by organizational factors. Consequently, the results of engagement primarily depend on the actions of the organization, management and culture; the practical meaning of studying organizational factors of engagement is determined by leadership and the culture of knowledge.

\subsection{Transformational leadership}

As it was indicated earlier, involved employees are a condition for the formation of a competitive advantage of enterprises [13]. Also, leadership is a necessity for the successful operation of enterprises in a modern competitive environment [14].

Rabiul M.K. and Yean T.F. confirmed that transformational leadership style significantly affects employee engagement [15]. The transformational leader influences the involvement of subordinates through inspirational communication with them [16].

Researchers Bouwmans M. [17], Wang B. [18], Lee Y. [19] and others confirm the positive relationship of the transformational leadership style with the high independence of employees, joint decision-making and feedback-oriented behavior. Therefore, to build engagement, transformational leaders empower their subordinates to achieve the long term company's goals and take into account the views of others.

Employee engagement refers to a transformational leadership style and manifests itself in leadership actions exemplifying entrepreneurship, responsibility and innovation.

The latent construction of "leadership" is defined by four elements in our empirical research questionnaire that have been converted into statements for analysis. The results of empirical testing are presented in Table 1 . They show that the selected elements have high discriminant validity (AVE $=0.688$ ), are internally consistent $(\mathrm{CR}=0.849)$ and reflect the high explanatory power of each of the questions of the latent construction.

Leadership behavior, which manifests itself in the form of mentoring, providing more independence to employees, orientation towards actions, both in the interests of employees and the organization as a whole, allows forming the involvement of personnel.

\subsection{Knowledge culture}

The culture of the organization is one of the important management tools in competitive organizations, capable of creating a corporate climate with trusting relationship, openness and participation [20]. The culture of knowledge strengthens the common goals of employees and the organization, supports fruitful work with the team, allows to determine the areas of staff development, taking into account the current competitive situation, participates in the formation of conditions for the growth of human capital.

Table 1. Factor loads of metrics included in latent constructions

\begin{tabular}{|c|c|}
\hline Metrics & $\begin{array}{l}\text { Factor } \\
\text { Loads }\end{array}$ \\
\hline \multicolumn{2}{|l|}{ Innovation $(\mathrm{CR}=\mathbf{0 . 8 0 6}, \mathrm{AVE}=\mathbf{0 . 7 2 0})$} \\
\hline Management innovation & 0.816 \\
\hline Product innovation & 0.859 \\
\hline Technological innovation & 0.870 \\
\hline \multicolumn{2}{|l|}{ Engagement $(\mathrm{CR}=\mathbf{0 . 7 1 6}, \mathrm{AVE}=\mathbf{0 . 6 3 9})$} \\
\hline $\begin{array}{l}\text { Employees, on their own initiative, make } \\
\text { suggestions for improving the company's } \\
\text { products or services }\end{array}$ & 0.775 \\
\hline $\begin{array}{l}\text { Despite personal interests, employees } \\
\text { voluntarily strive to achieve the desired } \\
\text { results with additional effort }\end{array}$ & 0.843 \\
\hline $\begin{array}{l}\text { Most employees require minimal } \\
\text { management oversight to achieve the desired } \\
\text { results }\end{array}$ & 0.778 \\
\hline \multicolumn{2}{|l|}{$\begin{array}{l}\text { Transformational Leadership }(\mathrm{CR}=\mathbf{0 . 8 4 9} \\
\mathrm{AVE}=\mathbf{0 . 6 8 8})\end{array}$} \\
\hline $\begin{array}{l}\text { Leaders know how to inspire their } \\
\text { subordinates to solve difficult work issues }\end{array}$ & 0.797 \\
\hline $\begin{array}{l}\text { Leaders prefer to consider the opinions of } \\
\text { the people around them }\end{array}$ & 0.833 \\
\hline $\begin{array}{l}\text { Leaders empower employees to achieve the } \\
\text { strategic goals of the organization }\end{array}$ & 0.827 \\
\hline $\begin{array}{l}\text { Leaders demonstrate innovative and } \\
\text { entrepreneurial patterns, and take } \\
\text { responsibility for their decisions }\end{array}$ & 0.861 \\
\hline \multicolumn{2}{|l|}{$\begin{array}{l}\text { Knowledge culture }(\mathrm{CR}=\mathbf{0 . 8 9 2}, \mathrm{AVE}= \\
\text { 0.699) }\end{array}$} \\
\hline $\begin{array}{l}\text { The organization approves and supports the } \\
\text { desire of employees to learn }\end{array}$ & 0.821 \\
\hline $\begin{array}{l}\text { The organization approves and supports } \\
\text { teamwork }\end{array}$ & 0.875 \\
\hline $\begin{array}{l}\text { The organization encourages employees to } \\
\text { take initiative and generate ideas for product } \\
\text { and manufacturing process improvement }\end{array}$ & 0.820 \\
\hline $\begin{array}{l}\text { The organization endorses the independence } \\
\text { of employees in defining and achieving their } \\
\text { goals }\end{array}$ & 0.867 \\
\hline $\begin{array}{l}\text { There is a high degree of trust between } \\
\text { people in the company }\end{array}$ & 0.793 \\
\hline
\end{tabular}

In the questionnaire, the authors chose 5 metrics for the analysis of the latent structure "Knowledge culture", 
while the choice of metrics was based on the experience of previous studies and relied on the peculiarities of the culture of knowledge of organizations that manage their competitiveness. These 5 metrics are in Table 1 . The authors considered these constructions to be sufficient for studying the knowledge culture, relying on the principle of optimality when creating a questionnaire.

The latent construct "Knowledge culture" was tested in terms of validity and internal consistency, and their values were obtained: $\mathrm{AVE}=0.699, \mathrm{CR}=0.892$, respectively. Testing of the latent construction was carried out on the example of employees of various Russian enterprises. The results are in Table 1.

Knowledge culture directly affects employee engagement, as evidenced by many studies.

A jointly supportive organizational culture and excellent leader performance have significant effects on professional engagement and job satisfaction according to Meng J. and Berger B. K. [21].

Studies by Jena L.K., Pradhan S., Panigrahy N.P. [22] confirm that engagement establishes "a clear connection between the employee and the organization's activities" and provides a better understanding of the organization's goals, as argued by Hughes J.C. and Rog E. [23].

Farrell M.A. found that a learning orientation, which is part of organizational values, has a positive effect on organizational engagement [24].

Table 1 contains 4 latent constructs "Engagement", "Knowledge culture", "Transformational Leadership" and "Innovation" with their decoding metrics and an indication of the factor load.

\section{Results of the study}

Correlation analysis and one-factor models showed that knowledge culture and transformational leadership have a positive and significant impact on employee engagement, while engagement, in turn, has a significant impact on company innovation.

Further, the authors searched for the optimal configuration of studied variable interactions with a joint effect on innovation. Different models were tested and the final decision was taken considering the following issues. Firstly, theoretical justification and empirical evidence of previous studies regarding the relationship of the studied variables were taken into account. Secondly, the authors have chosen the final model based on the results of one-factor model and correlation analysis.

The final model was significant and indicated high quality with the Standardized Root Mean Residual (SRMR) equaled 0.08. Table 2 shows the estimated coefficients for the model.

One could see that the influence of knowledge culture (0.506) is twice as strong as the influence of transformational leadership (0.234) on the employee engagement of Russian enterprises. Together, they explain around $48 \%$ of the variation in the engagement variable. In turn, the variable "employee engagement" explains $23.6 \%$ of the variation in the dependent variable "innovation".

Table 2. Results of model estimation

\begin{tabular}{|l|c|}
\hline & $\begin{array}{c}\text { Original } \\
\text { Sample (O) }\end{array}$ \\
\hline Engagement -> Innovation & 0.486 \\
\hline Knowledge culture -> Engagement & 0.506 \\
\hline Leadership -> Engagement & 0.234 \\
\hline
\end{tabular}

Thus, we obtained empirical evidence about the positive and significant impact of knowledge culture and transformational leadership on employee engagement in order to increase company's innovation.

\section{Conclusions}

In this study, a hypothesis was put forward about the influence of employee engagement on the growth of the number of innovations in the organization due to the formation of a culture of knowledge and leadership.

Four latent constructs were tested with fifteen element questions including: innovation; involvement; culture of knowledge; transformational leadership. For adaptation to a Russian-speaking audience, the questions-elements were selected from the works of English-speaking authors. The high discriminant validity and internal consistency of all investigated constructs confirmed the results of the empirical analysis. This confirms the contribution of the authors of this article to the empirical knowledge of the elements of "Innovation", "Engagement", "Knowledge culture" and "Transformational Leadership" for the academic community in order to conduct further research in this area.

The work shows that the culture of knowledge has the greatest influence on the involvement of personnel. Leadership has a direct and positive, but smaller impact on employee engagement. There is no doubt that a small sample makes the resulting empirical knowledge limited. Accordingly, this factor should be taken into account when formulating conclusions and practical recommendations.

The results of the study of the formation of involvement due to the positive influence of organizational mechanisms reflect the data on 110 Russian enterprises.

Both businesses and researchers can use the findings for their own purposes. Top management of the companies could take into account these empirical results by implementing human resource management practices with the aim to increase company innovation. Scholars could apply proposed research framework to the analysis of other samples and provide comparative analysis. 


\section{References}

1. Oslo Manual. Recommendations for collecting and analyzing innovation data. Third edition. Translation from English. Second revised edition. M. 31-107. (2010)

2. Kincentric. Culture\&Engagement. Wired for Engagement. Improving Engagement Through Better Hiring. Retrieved from: https://www.kincentric.com//media/kincentric/2019/november/culture/wiredfor-engagement.pdf

3. O.V. Mitina. Experimental Psychology, 1, 142 (2008)

4. Perm National Research Polytechnic University Publishing. Schumpeterian Readings. The Ninth International Scientific Research Conference Proceedings. 241 (2020)

5. World Bank. Retrieved from: https://data.worldbank.org/indicator/NY.GDP.M KTP.KD.

6. I.A. Schumpeter. Economic development theory. Capitalism, socialism, democracy. 864 (2007)

7. W. Kahn. The Academy of Management Journal. 33 (4), 692-724. (1990).

8. The Power of Gallup's Q12 Employee Engagement Survey Retrieved from: https://www.gallup.com/access/323333/q12employee-engagement-survey.aspx

9. W.H. Macey, B. Schneider. The Meaning of Employee Engagement. Industrial and Organizational Psychology. 1(1), 3-30 (2008).

10. B. Shuck. Human Resource Development Review, 10. 304-328 (2011).

11. C. Bailey, A. Madden, K Alfes, L. Fletcher. International Journal of Management Reviews. 19, 31-53 (2017)

12. Insights from Culture Amp's 2018 employee benchmarks Retrieved from: https://www.cultureamp.com/blog/2018employee-benchmarks/

13. S.L. Albrecht, A.B. Bakker, J.A. Gruman, W.H. Macy, A.M. Sachs J. Organ. Eff. People are performing. 2 (1), 7-35 (2015).

14. O. R. Mahdi, M. K. Almsafir.. Procedia - Social and Behavioral Sciences. 129, 289-296 (2014).

15. M. K. Rabiul, T. F. Yean. International Journal of Hospitality Management. 92, 102712 (2021).

16. Transformational Leadership: A Quick Start Guide: Growing, Supporting, and Empowering People to Amplify Change in Organizations. Retrieved from: https://static1.squarespace.com/static/571faf00c2 ea510eafddb70b/t/5c1f087121c67c0d67c426a8/1 545537650781/2018-Forum-TransformationalLeadership.pdf

17. M. Bouwmans, P. Runhaar, R. Wesselink, M. Mulder. Teaching and Teacher Education. 65, 71-80 (2017).

18. B. Wang, J. Qian, R. Ou, C. Huang, B. Xu, Y. Xia. Social Behavior and Personality: An international journal. 44 (7), 1201-1208 (2016).
19. Y. Lee, J. Kim. Public Relations Review. 47 (1), 101998 (2021).

20. M. Molodchik, C. Jardon. The Learning Organization. 22 (6), 306- 316 (2015).

21. J. Meng, B. K. Berger. Public Relations Review. 45 (1), 64-75 (2019).

22. L. K. Jena, S. Pradhan, N. P. Panigrahy. Asia Pacific Management Review. 23 (3), 227-234 (2018).

23. J.C. Hughes, E. Rog. International Journal of Contemporary Hospitality Management. 20 (7), 743-757 (2008).

24. M. A. Farrell. Marketing Bulletin. 10, 38-51 (1999). 